\title{
O DISPOSITIVO VIDEOGRÁFICO E AS NARRATIVAS DE SI MESMO E DO OUTRO: VIDEOCORPO
}

\section{THE VIDEO-BODY AND NARRATIVES OF THE SAME AND THE OTHER: VIDEOBODY}

Regilene Aparecida Sarzi-Ribeiro ${ }^{1}$ 


\section{Resumo}

Apresentamos este artigo sobre as narrativas de si mesmo e do outro por meio do estudo do vídeo Entre de Nina Galanternick. Partindo do argumento de que o corpo que performa para a câmera atua como um operador de sentido do dispositivo videográfico e que o sincretismo corpo-máquina age como protagonista da construção de identidade entre os sujeitos, buscamos aproximar o vídeo das ideias de programação e dispositivo, para defendê-lo como elemento performático, para além de um meio de registro ou documentação. Para fundamentação teórica optamos pelos autores Gilles Deleuze, Giorgio Agamben e Vilém Flusser e seus estudos sobre dispositivos e técno-imagens, Hans Belting e a relação entre corpo e imagem e Arlindo Machado e a arte do vídeo brasileiro. Conhecer as relações entre visibilidade e interação, corpo e vídeo, arte performática e linguagem videográfica nos permitiu compreender como se constroem o sentido da vida, das relações entre os corpos e as narrativas de si mesmo e do outro.

Palavras-chave: corpo; videoperformance; dispositivo videográfico; Nina Galanternick.

\section{Abstract}

We present this article on the narratives of oneself and the other through the study of the video Entre de Nina Galanternick. Starting from the argument that the body that perfor$\mathrm{ms}$ for the camera acts as a sense operator of the videographic device and that syncretism body-machine acts as the protagonist of the construction of identity between the subjects, we seek to bring the video of the ideas of programming and device, to defend it as a performance element, as well as a means of registration or documentation. For theoretical reasons we chose the authors Gilles Deleuze, Giorgio Agamben and Vilém Flusser and their studies on devices and techno-images, Hans Belting and the relationship between body and image and Arlindo Machado and the art of Brazilian video. Knowing the relationships between visibility and interaction, body and video, performance art and videographic language allowed us to understand how to construct the meaning of life, relationships between bodies and the narratives of oneself and the other.

Keywords: body; videoperformance; videographic device; Nina Galanternick.

ISSN: $2175-2346$

${ }^{1}$ regilenesarzi@faac.unesp.br 


\section{Corpo e vídeo, videocorpo: uma pesquisa}

Durante as primeiras investigações sobre o tema, observamos que havia um profícuo campo de estudo em aberto sobre as relações entre a experiência estética (filosofia), a presença do corpo (performance) e o vídeo (comunicação) como dispositivo-máquina passíveis de serem considerados por uma abordagem transdisciplinar. Observamos que o vídeo como produtor de linguagem e discurso em sinergia com o corpo e vice-versa têm muito a ser revelado pelo atual estágio da produção artística audiovisual brasileira em uma sociedade digital e imagética controlada pelas tecno-imagens.

Partimos da hipótese de que o vídeo ultrapassa a condição de dispositivo de registro e documentação da ação performática para se tornar, a partir de uma relação de sinergia com o corpo, um dispositivo performático - máquina para fazer ver e sentir a ação performática, prótese máquina que resulta em um híbrido videocorpo.

Assim, a proposta é investigar o surgimento de um possível conceito de performance expandida - videocorpo - resultante da sua fusão com o meio videográfico. Entre os objetivos da pesquisa está o questionamento do termo videoperformance como registro ou documentação de performances e a proposta de um novo termo videocorpo - para abarcar a complexidade de uma nova linguagem artística, fruto do vídeo apropriado como componente criativo da arte performática que gera o hibridismo corpo-video. O estudo aponta para a ampliação ou extensão do conceito de videoperformance, uma vez que a linguagem do corpo e a linguagem do vídeo em contágio se fundem e se tornam em um híbrido: o vídeo é a performance e a performance é o vídeo, alterando a experiência do corpo daquele que frui a performance expandida em vídeo.

Neste contexto nos interessam os vídeos cujas narrativas de si mesmo extrapolam o texto fixando-se na imagem e no som (narrativa audiovisual) e na relação do corpo de si mesmo e do outro tendo o vídeo como disparador e provocador de sentidos, local de encontro e constituição de identidade, troca e diálogo, identidade e alteridade: videocorpo.

Como nosso interesse sempre esteve voltado para a história da arte do vídeo brasileiro e as implicações dos registros em vídeos para a arte do corpo, e vice-versa, debruçamo-nos sobre o tema e partimos para investigação de dois aspectos inter-relacionados: o corpo como um operador de sentido do dispositivo audiovisual e o estudo do sincretismo corpo-máquina como protagonista da construção de identidade do sujeito performer e do espectador.

Com este entendimento, decidimos investigar como a videoperformance nos anos 1990, após duas décadas de videoarte e o uso do vídeo para registros de performances no Brasil, legitima aspectos experimentais da linguagem do vídeo e mantém o papel de mediação e construção de identidade e crítica social e politica.

Assim, buscamos descrever de que forma o embate entre o dispositivo (câmera de vídeo) e o corpo do artista se constituem um elemento estrutural construtor da linguagem do vídeo, sinônimo de produção artístico-midiática que amplia as experiências sensíveis do corpo. Um corpus de vídeos produzidos em interação com performances de artistas brasileiros foram pesquisados, dentre os quais optamos por apresentar neste 
artigo, o resultado da análise e articulações teóricas do estudo do vídeo Entre (1999) da artista carioca Nina Galanternick.

\section{0 meu corpo no corpo do outro}

Para analisar o vídeo Entre (1999), de Nina Galanternick, tomamos como eixos norteadores algumas questões: Qual a relação entre o corpo performático e a linguagem do vídeo? Como os aspectos formais (composição, espaço, luz, cor e textura) operam arranjos sonoro-visuais que tornam visíveis os corpos no vídeo analisado? Que sentido de si mesmo e do outro são processados? Como se dá a construção de sentido que gera o videocorpo?

No vídeo Entre, nos deparamos com cenas de um corpo feminino mostrado em detalhes, dos pés a cabeça passando por ventre, nádegas e órgãos sexuais cuja tonalidade de pele varia de um intenso rosáceo ao vermelho intenso e ao final, tons claros de pele branca quase sem cor (Figuras 1 e 2).

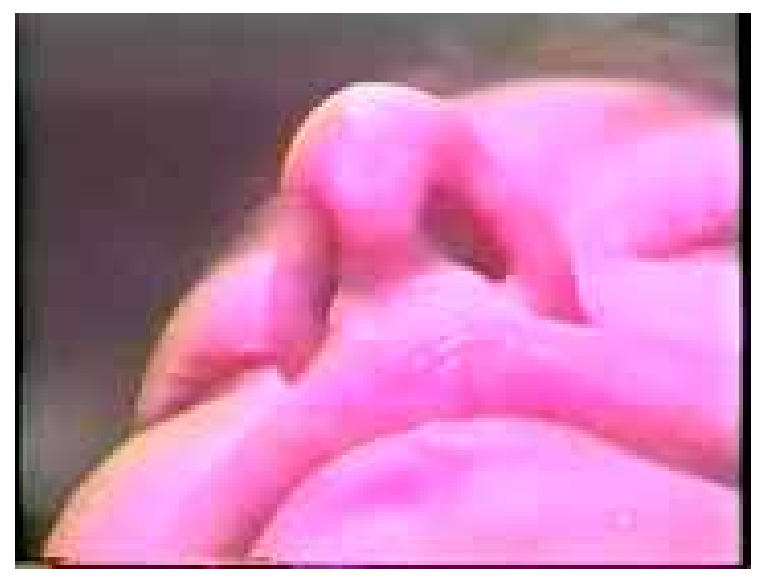

Fig. 1 - Frame do Vídeo Entre (1999) de Nina Galanternick. 06'. Colorido. Fonte: http://ninagalanternick.com/Entre-1

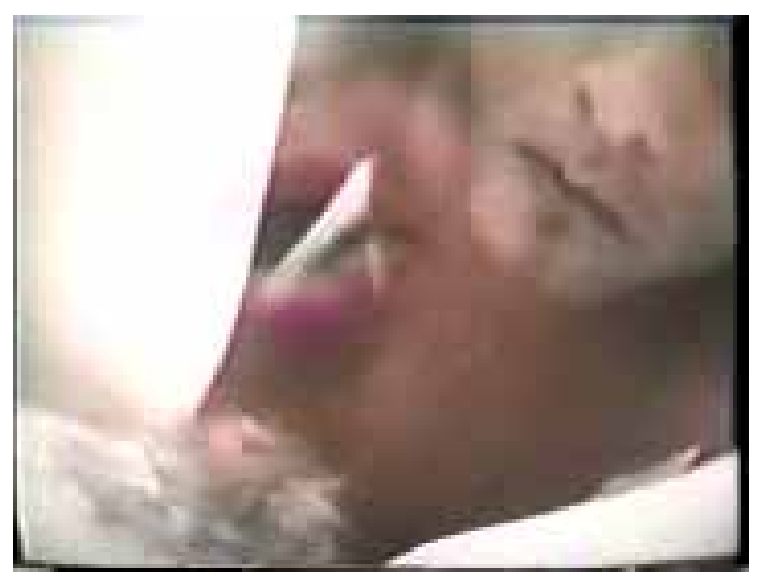

Fig. 2 - Frame do Vídeo Entre (1999) de Nina Galanternick. 06'. Colorido. Fonte: http://ninagalanternick.com/Entre-1

O corpo feminino é percorrido pela câmera de cima a baixo e enquadrado na intimidade para mostrar detalhes dos membros do seu rosto, cabelos, narinas, orelhas e boca. Outras cenas focalizam pormenores como pintas e manchas do corpo e 
membros como pés, nádegas e pelos da vagina. Tal como uma descrição, a câmera se projeta como um scanner, tornando visível o corpo em detalhes. No entanto, os modos de construção do sensível são despertados pela maneira como a câmera de vídeo fragmenta o que vê por meio do enquadramento e da aproximação em zoom, com ênfase para os tecidos do corpo e suas partes. A câmera faz o outro ver o corpo em si mesmo.

A programação para sentir as coisas do mundo por suas partes, ou em detalhes, é uma função programada pelo dispositivo da máquina da ordem do midiático (comunicação), uma vez que está na essência da linguagem do vídeo a estrutura fragmentar (SARZI-RIBEIRO, 2012). A programação da máquina visa orientar o olhar do usuário para um contato com o mundo por meio da descontinuidade e das relações cotidianas da ordem e da estabilidade. A câmera em sua programação para um olhar fragmentário conduz a experiência visual para um contágio de si mesmo, por meio dos enquadramentos fechados e lentes macros.

A visualidade revelada por figuras orgânicas e compostas de linhas curvas se contrapõe às figuras geométricas, retilíneas. Os cortes e planos detalhes mantêm quem quer que esteja a ver o corpo o tempo todo muito próximo dos detalhes destes orifícios e entradas. O olhar é levado a permanecer conectado a estas partes do corpo, que o convidam a entrar. Essa composição é resultado do enquadramento fechado das cenas que focaliza a parte do corpo que se quer reconhecer pela palavra de ordem: entre.

O cinetismo da câmera é um traço da linguagem audiovisual que gera movimentos compostos de ritmo (rápido e lento) e velocidade (acelerado e desacelerado) marcados pela continuidade e descontinuidade nas cenas, e a parcialidade com que este corpo se faz visível. $O$ enquadramento aproximado e o zoom avalizam que aquelas formas, ovais e circulares dos membros do corpo compostos de orifícios, são percursos, trajetos, passagens e podem ser adentrados. Os percursos sugeridos por triangulações e circunvoluções, resultantes do contorno das formas e partes do corpo, são enquadrados por planos fechados e zooms que dirigem quem está assistindo ao vídeo de fora para dentro, do exterior social e coletivo e para o interior privado e íntimo, configurando um ajuste à programação do dispositivo videográfico (Figura 3).
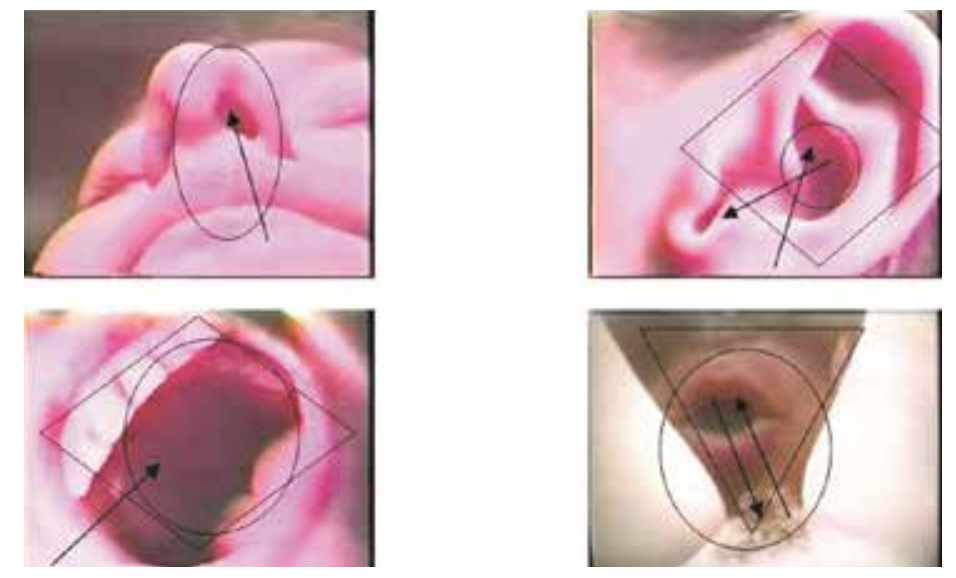

Fig. 3 - Frames do Vídeo Entre (1999) de Nina Galanternick. 06’. Colorido. Estudo dos enquadramentos, triangulações e circunvoluções que conduzem a experiência do corpo no vídeo-corpo.

Fonte: http://ninagalanternick.com/Entre-1 
O estudo do sincretismo entre o sonoro e o visual revelou que o sistema visual opera em cooperação com o sistema verbo-sonoro. No primeiro contato com o vídeo e o titulo Entre, ordena a ação, mas ao longo das cenas essa ordem vai se concretizando nas formas, nas cores e na materialidade do corpo. Quando se percebe, o espectador está contagiado pelos acessos ao corpo e se encontra diante do inusitado: o meu corpo está dentro do corpo do outro.

A arte performática se estende de dentro para fora e de fora para dentro do vídeo. $O$ encantamento ou estranhamento que sentimos diante dos portais de acesso ao corpo são materializados pela linguagem videográfica que opera na ligação entre cenas rápidas e lentas e superfícies planas em detrimento às aberturas do corpo, composta pelo caminhar da câmera. Por todas estas relações, o corpo do vídeo Entre é um corpo conhecido na sua intimidade por um dispositivo maquínico que se aproxima sempre com o intuito de tornar visíveis os portais de acesso ao corpo.

O corpo que performatiza diante da câmera se entrega para o dispositivo tornando o vídeo, ele mesmo, um componente da performance, corpo e vídeo se integram e o resultado é um hibrido, videocorpo.

Imagens se somam a sons de diferentes espécies produzidos pelo próprio corpo como gemidos, sopros, estampidos de beijos e chupadas. A organização sonora de Entre se constitui de ruídos e sons metálicos, mas ao mesmo tempo sons provenientes do corpo, fluídos e líquidos corporais, sons de batidas do coração, gemidos, sons de assovios, chupadas, sons resultantes de beijos, sopros.

A sonoridade do vídeo se modifica quando surge em cena uma boca masculina, de tom avermelhado, que verbaliza frases na direção de outro corpo, também rosáceo. O rosto masculino, que se faz ver por meio do nariz, boca e queixo, fala para dentro de algum lugar e a câmera apenas sugere este espaço para onde o homem projeta sua fala, ou melhor, seus gritos. O homem pronuncia, enfática e freneticamente, trechos de poesias de Clarice Lispector, Antônio Artaud, Mário Quintana, Wiliam Blake e Raduan Nassar.

No texto verbal, notamos que os sons proferidos por palavras são resultado de uma colagem de fragmentos de textos destes diferentes autores, recompostos em um denominador comum sobre o corpo. O corpo masculino fala, grita de frente para a tela do vídeo, para o espectador, e descarrega sua fúria de palavras entre as pernas do corpo feminino.

$\mathrm{Na}$ análise depreendemos que o corpo masculino se torna presente por meio das palavras lançadas e impostas para dentro do corpo feminino. O corpo performático masculino nos remete a valores e questões de gênero presentes nas relações entre duas pessoas. Interpretamos por oposições, o poder do corpo masculino versus a fragilidade do corpo feminino, o desejo de se deixar penetrar versus o prazer da penetração, e a imposição de valores e usos do corpo. O vídeo promove um contínuo para dentro do corpo e um contínuo entre os corpos. O discurso audiovisual de Entre tem a clara intenção de levar o espectador a entrar no corpo por meio daquilo tudo que possa simular um entre corpos. $O$ videocorpo apresenta a ação do corpo de si mesmo e do outro e em uníssono integra os corpos que performatizam para dar vida a obra. 
No video Entre os fragmentos do corpo são elementos estéticos que presentificam o corpo e a sexualidade, exibidos e mediados pelo teor lírico e romântico que transformam o ato sexual em um discurso sensivel do corpo. De fato, trata-se do corpo físico e orgânico, mas, a experiência é a de um corpo social e político exposto às questões de gênero e domínio entre os corpos. Um corpo vivido que se torna presença a partir de caminhos que querem burlar o mecânico e o automático para ser sentido como algo vital e fundamental à própria condição existencial do corpo.

O contágio no vídeo Entre pode ser descrito como uma interação entre sujeitos que compartilham o ato de entrar e adentrar o corpo por percursos (trajetórias) fisiológicos, sensuais e sensoriais que levam ao contato direto consigo mesmo por meio do corpo do outro, num constante ir e vir para dentro e para fora do corpo. O contato que se estabelece entre os corpos em interação constrói a identidade do sujeito e as narrativas de si mesmo e do outro, no vídeo Entre.

$\mathrm{Na}$ tela de vídeo se lê a palavra Entre, em letras brancas sob um fundo escuro. A primeira leitura da palavra certamente não traz a complexidade daquilo que se pretende, mas já introduz aquele que se quer conduzir para dentro do vídeo, indicando-lhe a ação que deve realizar: entre. A leitura da palavra remete-se à ao iniciar do filme, por meio da epistemologia do verbo entrar: para dentro de, aquilo que se coloca no meio de, entre duas coisas. No momento seguinte, aquele que assiste ao vídeo passa a se defrontar com um corpo na tela. Na primeira sequência de cenas o que se vê é a parte de cima de uma cabeça e um couro cabeludo, do qual se reconhecem as raízes do cabelo repartidas ao meio e o couro de pele clara, bem no centro da tela. Os cabelos castanhos claros são vistos no conjunto da cena pelo corpo enquadrado, e por meio de um grande close em plongée retalha o corpo para destacar seus detalhes e instalar os actantes do enunciado logo no começo do vídeo, bem próximos do corpo. Pela proximidade intensa com o corpo, o enunciador seduz o corpo de fora a entrar no corpo de dentro do vídeo.

Os atores instalados na enunciação partem na sua jornada conjunta que os levará à construção e compreensão do sentido do vídeo Entre. No corpo enquadrado pela tela do vídeo se reconhecem a pele rosada e clara de um umbigo e da região da cintura e do ventre, recobertos de pêlos claros e pequenas manchas de pele. $O$ corpo que assiste ao vídeo é convidado a se aproximar mais uma vez do corpo videografico tateando visualmente a forma sensual do umbigo, cuja oval direciona o olhar de quem olha para o seu interior, provocando ainda mais a sensação de adentramento. A tonalidade escura e os movimentos de abrir e fechar do umbigo atrai o olhar para a profundidade de seu interior e reitera no corpo do observador a sensação de adentrar o corpo.

Os olhos, agora vistos na tela do vídeo, são olhos femininos, e o corpo que agora se vê se sabe ser um corpo de mulher. Ela encara o vídeo com olhos amendoados, sobrancelhas desenhadas e olhar melancólico, e juntos compõem um rosto parcial que ora se mostra pelo olho esquerdo, ora pelo olho direito. Em cada quadro do vídeo se tem um encontro com os olhos da mulher. $O$ corpo de quem se dispôs a ver o vídeo se depara com um corpo feminino que tem manchas na pele. Pernas, braços, pescoço e rosto ora são vistos de frente, ora de lado, ora por cima, ora por baixo, e revelam a forma de uma mulher que tem pele branca, suave, composta por manchas avermelhadas. Mas, também, destacam um corpo quente, cuja mancha escura nas 
nádegas e na unha do dedo do pé leva a crer que se trata de um corpo que escancara sua intimidade, seus detalhes mais pessoais e íntimos.

Essas manchas corpóreas são marcas na superfície do corpo e como registros genéticos, pintas, deixam sinais causados pela exposição ao sol intenso e machucados ou hematomas produzidos por pressões ou topadas do corpo contra algo externo a ele. Estas manchas são marcas produzidas no corpo por fatores externos que acabam resultando em manchas internas, que permanecem como registros e memórias do corpo internalizadas na relação com o mundo externo. É esse corpo que se reconhece em cena.

Em algumas cenas do vídeo Entre se perde a referência da parte do corpo exibida, do corpo que performatiza, na medida em que o que se vê na tela se resume a manchas rosadas que tomam todo o quadro do vídeo. Ao corpo contemplador se oferece um rosto de perfil e cabelos castanhos longos, escuros, em movimento e em parte presos atrás das orelhas esquerdas. Uma orelha, grande, é o caminho por meio da qual pode se adentrar o corpo mais uma vez. Por entre as formas sinuosas compostas de linhas orgânicas da orelha, que são um convite ao tato, o corpo que assiste encontra as entradas pelas quais o seu corpo, aqui de fora, submerge e penetra as partes escuras e profundas do corpo lá de dentro, o corpo do performer.

$\mathrm{Da}$ orelha emergem relevos iluminados e canais de acesso que tornam consumado $o$ ato de transpor o corpo, de fora para dentro, por meio do pequeno orifício que se reconhece na entrada da orelha. Ao fazer esse percurso o corpo se descobre na sinuosidade e sensualidade do membro composto de linhas ondulantes e labirínticas. O olhar percorre todo o corpo de forma fugaz e realiza um efêmero caminhar, veloz e frenético, que passa pelas pernas da mulher, umbigo e ventre, percorrendo seu corpo até se fixar sobre os pêlos escuros do órgão sexual feminino.

Este olhar não é nem um pouco sutil, pelo contrário é indiscreto e curioso, embora disfarce passando rapidamente os olhos pelas partes do corpo que quer ver, desfocando a visão do corpo para aparentar timidez. Essas entradas, rápidas ou lentas, pelo corpo através da velocidade das cenas, escancaram o ritmo do ato que leva o outro para dentro do corpo devagar ou muito depressa. Pelos caminhos da indefinição da imagem do corpo e das formas sinuosas se constroem os efeitos de sentido que podem ser interpretados como penetrações densas ou acessos superficiais que se projetam tanto no corpo de quem adentra quanto de quem é por ele adentrado.

O corpo penetrado se sente acuado e cerra os dentes, se fecha diante daqueles que estão a possuí-lo. Estes que adentram, por sua vez experimentam a percepção de dois corpos num corpo só, quando se deparam com uma boca e dentes cerrados dentro do corpo que tem a boca aberta. O corpo de quem aprecia se multiplica em vários corpos, primeiro na forma de olhos que se projetam por toda extensão do feminino e depois no do outro que se vê disseminado pelos olhos que se colocam a ver, por meio de todos os membros. O corpo de um se transforma nos olhos do outro, o corpo coletivo no individual.

O corpo que viveu a experiência de adentrar o seu próprio corpo, através do adentrar o do outro, foi transformado pelos estados de alma do outro, euforia, prazer, aversão, gozo, assedio e sedução, sentimentos e sensações que se encontrou dentro do outro pelo estar dentro de si mesmo. O corpo interno, que foi experimentado, 
adentrado por partes e observado por olhos que tudo vêm e superfícies corpóreas que tudo sentem, é agora um corpo tátil. Competente estesicamente se tornou um corpo sensível que passa a língua pelos objetos, livros e folhas de livros tocando-os com um membro interno para trazê-los do mundo externo para dentro e se tornar dessa forma parte deles, como peles culturais alteradas por contatos externos. Não se quer mais estar fora e se convence do corpo dentro, entre, e com ele passa a se movimentar, a interagir e a alterar o mundo externo após se reconhecer nele por dentro.

O corpo de mulher se apropria do conteúdo interno de um livro por meio de um canudo - objeto mediador, que se coloca entre os corpos. O canudo entre o corpo de mulher e o corpo do livro, por estar no meio, serve de acesso aos corpos (Figura 4).
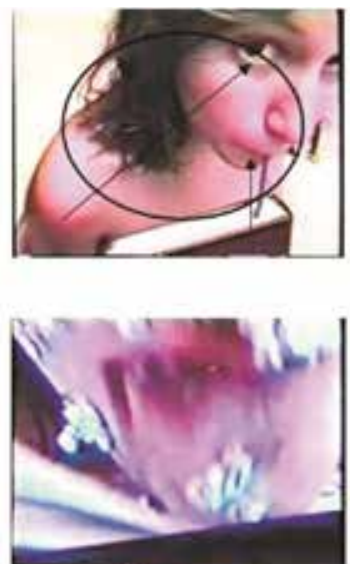

Fig. 4 - Frames do Vídeo Entre (1999) de Nina Galanternick. 06'. Colorido. Estudo da fusão entre corpo e vídeo e tradução do dispositivo videográfico em dispositivo performático.

Fonte: http://ninagalanternick.com/Entre-1

O contato direto entre o video mais o corpo se faz no momento em que estes se contagiam pelo olhar e pelos sentidos daqueles que sentem contagiados e absorvidos, o sentido da mediação dentre os corpos, o sentido de estar entre. Essa fusão entre video e corpo se dá pela tradução do dispositivo videográfico em um dispositivo performático, ao se tornar um híbrido videocorpo.

Um terceiro corpo aparece para se colocar em meio aos dois primeiros e sua presença é incômoda e forte. Trata-se da presença, nas últimas sequências do vídeo, da cabeça de um homem que fala freneticamente para dentro de algum lugar. Este lugar está aberto, e assim se mantém, por que o homem a segura com os seus próprios dedos. O rosto do sujeito, que se impõe, é avermelhado, ele parece furioso e nervoso, e sua pele rosada é iluminada por uma fonte intensa de luz que o toma pela boca para fazer ver sua atitude claramente na tela. O corpo feminino perde a vida e perde a cor, sua pele rosada se desbota até atingir tons de cinza, preto e branco. $O$ corpo daquele que contempla se esfria, perdendo a força e o calor, sinais vitais da presença da vida. O dentro, quente e vivo, se esvai para fora do corpo, frio e morto.

O corpo, comovido pelo contato com o outro, permanece a observar as pernas femininas que se encontram abertas, deixando à mostra os pelos escuros da vagina. O terceiro sujeito, corpo de homem, também se vê comovido e grita para dentro do órgão sexual feminino frases sem nexo. A poesia se confunde com os gritos enfurecidos do corpo masculino, que jorra para dentro do corpo feminino aos jatos palavras e 
gritos. O adentrar o corpo gritando, sua presença se consuma em meio às pernas da mulher e o masculino é figurativizado no vídeo pela cabeça masculina, que pode ser interpretada no discurso como sendo o órgão sexual masculino em cena.

Os corpos, feminino e masculino, comovidos pelo ato de comunhão entram pelos corpos de si mesmos e dos outros pela pele, olhos, narinas e orifícios, conduzidos pelas imagens, pela poesia, pelos sons e gemidos do corpo. Mas, acima de tudo, pelas entranhas descobertas pelo caminhar dos corpos para que juntos experimentem o êxtase da penetração mutua dos corpos, o entre corpos, dado a experimentar pelo dispositivo vídeo em fusão com o corpo do performer.

O entre, ato desejado e permitido em comunhão, se realiza através do adentrar e mediar dos corpos no ato sexual e no ato performático. As identidades corpóreas de um e de outro se confundem na medida em que o corpo feminino se reveste de olhos e sinais de nascença, como singularidades do sujeito, mas coletividades, por que agora são compartilhados pelo vídeo. Características como cor da pele, cor dos olhos e dos cabelos assim como linhas de expressão e sinais de nascença são agora traços individuais comuns a todos aqueles que experimentaram o vídeo. $O$ corpo adentrado é o corpo adentrado de todos. O meu corpo é o seu corpo. Eu me encontro em você.

\section{0 dispositivo videográfico - considerações finais}

Quando investigamos um conjunto de performances registradas por vídeos dos anos de 1990 ficou claro que, em sua maioria, estas não buscam, como nos anos 1970, somente o registro da ação do corpo, mas são obras nas quais a imagem do corpo sofre intervenções dos recursos gráficos e audiovisuais da tecnologia digital (edição e montagem) e que deles resultam corpos múltiplos e multifacetados, fragmentados, sobrepostos, mixados, articulados e recompostos que intensificam a linguagem tanto da performance quanto do vídeo - o videocorpo.

A evolução da tecnologia e as mudanças no contexto político e cultural interferem de modo significativo na produção videográfica contemporânea. Pensar o dispositivo como um aparelho para fazer ver e falar conforme Michael Foucault, citado por Gilles Deleuze (1996), representa acionar a discussão sobre as relações entre obra, artista e público. Quem vê, o como vê e o que é visto fazem parte de um mesmo sistema autopoiético (CAPRA, 2011), tal como em uma ecologia da criação na qual cada elemento se define necessariamente na relação com o outro.

Gilles Deleuze comenta algumas características dos dispositivos também destacadas por Michel Foucault (2003), como as curvas de visibilidade e as curvas de enunciação elementos presentes nos dispositivos que levam ao fazer ver e fazer falar, tornar visível, discursivizar e sentir as experiências do mundo, de habitar e presentificar por meio da visibilidade, a saber:

A visibilidade é feita de linhas de luz que formam figuras variáveis. [...] cada dispositivo tem seu regime de luz [...] distribuindo o visível e o invisível [...] os enunciados por sua vez, remetem para linhas de enunciação sobre as quais se distribuem as posições diferenciais dos seus elementos. [...] não são sujeitos nem objetos, mas regimes que é necessário definir pelo visível e pelo enunciável, com 
suas derivações [...] em cada dispositivo, linhas atravessam limiares em função dos quais são estéticas, científicas, políticas, etc. (DELEUZE, 1996, s/p).

Quando observamos o vídeo e como ele é utilizado pela arte performática como dispositivo performático notamos que estamos diante de inúmeras derivações que o vídeo sofre com relação ao seu papel como instrumento de registro do real, como experiência espaço-temporal. O vídeo como um dispositivo é composto por inúmeras possibilidades técnicas, estéticas e poéticas subordinados a programações maquínicas, mas também a variações de direções e resultados estéticos híbridos que envolvem um saber, um poder e a subjetividade de quem opera e frui.

O saber, tal como o poder compõe duas dimensões que são totalmente variáveis no interior de um dispositivo e estão associadas a capacidade, ao conhecimento e a ação. A dimensão da subjetividade não se refere a um saber ou poder, mas a um processo de individuação que escapa às forças estabelecidas pelo dispositivo como o saber necessário ou adquirido para operar este dispositivo, mas uma competência para manipular e alterar a programação inicial do dispositivo. São linhas que rompem que fraturam a organização inicial do dispositivo para dentro dele gerar uma nova condição. A subjetivação é autopoiética e com autonomia gera novos discursos que potencializam o dispositivo, como o videocorpo que aqui defendemos. $E$ é isso que observamos nas performances em vídeo ou videoperformances que ganham cada vez mais o status de linguagem hibrida - videocorpo que permite ao vídeo superar a sua condição de registro para se tornar ele mesmo um componente performático.

O corpo durante o ato performático em frente a uma câmera de vídeo passa por um processo de subjetivação que contamina o vídeo e sua linguagem e ao mesmo tempo é contagiado pelo dispositivo videográfico, pelos enquadramentos para ser um corpo+vídeo. O vídeo por sua vez se conecta tão intensamente ao corpo que performatiza, que reage tornando-o visível de forma singular - videocorpo. Corpo (mais) vídeo se tornam inseparáveis, se integram em um único dispositivo performático em que homem e máquina se hibridizam para fazer ver e falar: visível e enunciável de forma autônoma e subversiva.

A máquina, considerada aqui como um dispositivo para fazer ver e falar se torna muito mais do que um meio de registro somado à resistência e consciência política que os pioneiros da videoarte, sobretudo no Brasil, tinham diante do poder totalitarista, representado pelo governo militar da época e pela mídia televisiva, visando questionar autoridades e tabus.

O filósofo italiano Giorgio Agamben se debruça sobre as ideias de Foucault sobre o dispositivo e o transporta para outro contexto, tecendo conexões com o sistema religioso para buscar a origem do dispositivo dentro da cultura ocidental. Neste sentido, interessa a discussão que Agamben levanta sobre dois pontos: a epistemologia do termo e o conceito de profanação como postura transgressora frente ao poder disciplinar dos dispositivos.

O termo latino dispositio, do qual deriva o nosso termo 'dispositivo', vem, portanto, para assumir em si toda a complexa e sfera semântica da oikonomia teológica. Os dispositivos, dos quais fala Foucault, estão de algum modo conectados a esta herança teológica, podem ser de algum modo reconduzidos à fratura que divide 
e, ao mesmo tempo, articula em Deus ser e práxis, a natureza ou a essência e o modo em que ele administra e governa as criaturas (AGAMBEN, 2005, p.12).

No entanto, a despeito desta relação dos dispositivos com o poder sagrado que Agamben revela, cabe refletir sobre a nossa estratégia frente aos dispositivos na era pós-capitalista marcada por uma "gigantesca acumulação e proliferação dos dispositivos" já que eles existem na história da humanidade desde que o homo sapiens surgiu.

[...] a estratégia que devemos adotar no nosso corpo-a-corpo com os dispositivos não pode ser simples, já que se trata de nada menos que liberar o que foi capturado e separado pelos dispositivos para restituí-lo a um possível uso comum. [...] é nesta perspectiva que gostaria agora de falar-lhes de um conceito [...] que provém da esfera do direito e da religião romana [...] a profanação (AGAMBEN, 2005, p.14).

Conforme Agamben no direito romano, as coisas consideradas pertencentes aos deuses eram sagradas ou religiosas e não podiam ser comercializadas ou usadas pelos homens sendo retiradas da esfera comum para serem elevadas ao "consagrado", com o sagrado e separado do humano. Neste sentido, todo ato que violasse ou transgredisse essa lei e restituísse estas coisas à propriedade dos homens era considerada uma profanação. Agamben esclarece que o dispositivo dentro deste sistema que regula a separação é o sacrifício. "A profanação é o contradispositivo que restitui ao uso comum àquilo que o sacrífico havia separado e dividido" (AGAMBEN, 2005, p.14).

Curioso notar que ao investigar o dispositivo sob a ótica de Agamben, suas ideias nos remeteram aos conceitos de Vilém Flusser sobre as imagens técnicas e os dispositivos técnicos que as produzem. Flusser defende a programação como processo civilizatório, no qual a arte pode ser um instrumento de libertação dos homens para romper o poder das técno-imagens e empreender a experiência estética pura. Flusser descreve uma trama de relações entre sujeitos, aparelhos e sociedade para nos mostrar como "[...] a intenção programada no aparelho é a de realizar o seu programa, ou seja, programar os homens para que lhe sirvam de feedback para o seu continuo aperfeiçoamento" (FLUSSER, 2011, p. 62). Essas estratégias podem ser consideradas como um jogo de poder do dispositivo que se desdobra em uma rede de relações entre os elementos que o constitui como indica Flusser, usando como exemplo o fotógrafo e a programação da câmera fotográfica:

O jogo com símbolos passa a ser jogo do poder. Trata-se, porém, de jogo hierarquicamente estruturado. $\mathrm{O}$ fotógrafo exerce poder sobre quem vê suas fotografias, programando os receptores. $\mathrm{O}$ aparelho fotográfico exerce poder sobre o fotógrafo. A indústria fotográfica exerce poder sobre o aparelho. E assim ad infinitum. No jogo simbólico do poder, este se dilui e se desumaniza. Eis o que sejam "sociedade informática" e "imperialismo pós-industrial" (FLUSSER, 2011, p. 47).

Em síntese, o sujeito fotógrafo se apropria do aparelho para domínio sobre os outros, para expressar e comunicar seus discursos e, sobretudo para projetar-se sobre os outros sujeitos na forma de imagens (discursos visuais), ao passo que o aparelho visa programar os homens para que estes lhe sirvam de agentes de aperfeiçoamento 
e evolução técnica. Mas preferimos pensar na complexa relação que envolve o dispositivo: aparelho-tecno-imagens-sujeito-sociedade. Flusser ressalta:

[...] o aparelho fotográfico é produto do aparelho da indústria fotográfica, que é produto do aparelho do parque industrial, que é produto do aparelho socioeconômico e assim por diante. Através de toda essa hierarquia de aparelhos, corre uma única e gigantesca intenção [...] fazer com que aparelhos programem a sociedade para um comportamento propício ao constante aperfeiçoamento dos aparelhos (FLUSSER, 2011, p. 63).

De igual forma, podemos pensar no uso programado do vídeo na sociedade capitalista atual que se espalha pelos mais variados dispositivos: do computador ao celular. No entanto, este percurso programador e de interação não é linear e se constitui em inúmeros devires e desvios de rotas, que resultam na transformação do vídeo em um dispositivo performático que extrapola sua função de documentação para se tornar um dispositivo de identificação entre sujeitos, interação e mediação de experiências entre corpos, narrativas do eu e do outro.

Como uma rede ou trama, o dispositivo de Foucault parece dialogar com o conceito de programação de Flusser, que também prevê possíveis avanços no nível de consciência do sistema ou ecologia (CAPRA, 2011) das imagens técnicas. Segundo Flusser, nos somos programados pelas imagens a tal ponto de não questioná-las e isso revela o quanto estamos totalmente imersos, automatizados e domesticados pelas tecno-imagens. Este comportamento acrítico está cegando nossa liberdade de dialogar com as imagens.

A saída seria a retomada do controle sobre os aparelhos para que fossem possíveis diálogos criativos, diálogos livres a partir de um distanciamento ou reflexão, como a que arte provoca, para que as pessoas tomassem consciência, para que profanassem o uso do vídeo. E neste contexto, entendemos que a performance e o vídeo ao se tornarem uma linguagem hibrida, como defendemos por meio da análise do vídeo Entre de Nina Galanternick, promovem um desvio da linguagem tanto da performance quanto do vídeo e rompem com a programação do dispositivo videográfico, profanando-o para que ele supere o seu status de registro para se tornar em simbiose com o corpo, outra linguagem, que não é só a do corpo nem só a do vídeo, mas outra.

É neste ponto que relacionamos Flusser ao conceito de "profanação" de Agamben. Profanar o uso programador do vídeo ou da imagem videográfica, pensada apenas como registro ou documentação das performances, seria restituir o papel criativo do dispositivo video mais corpo mais ação, para traduzir-se em performance expandida ou performances-vídeo - videocorpo - devolvendo-o à propriedade dos homens livres para novos diálogos com o corpo a partir do vídeo. Segundo Flusser:

[...] das virtualidades dialógicas inerentes a imagens: que são infinitamente maiores que as virtualidades dos textos [...] De tal consciência imagística nova se abririam horizontes para diálogos infinitamente mais informativos [...] de riqueza criadora [...] seríamos de repente todos 'artistas' (aqui, o termo 'arte' engloba ciência, política e filosofia) (FLUSSER, 2008, p. 87). 
Ocorre que para o historiador da arte alemão Hans Belting meio, imagem e corpo são instâncias inseparáveis e interdependentes que se entrelaçam e confundem-se no ato de sua manifestação e isso vale também para as performances-vídeo que nos interessam. Para ele cabe pensar a imagem no cruzamento entre o meio (vídeo + performance) que a produz e o corpo (fruidor) que a consome. Belting afirma que a mídia

[...] é para ser entendida não em seu sentido usual, mas no sentido de agente pelo qual imagens são transmitidas, enquanto corpo significa tanto o corpo que performatiza quanto o que percebe, do qual as imagens dependem na mesma medida em que dependem de suas respectivas mídias. Eu não falo de mídia como tal, obviamente, nem falo do corpo como tal. Ambos modificam-se continuamente (o que nos permite falar de uma história das tecnologias visuais do mesmo modo que também estamos familiarizados a uma história da percepção), mas em sua presença sempre mutante eles têm mantido seu lugar na circulação de imagens (BELTING, 2006, p. 33).

Em suma, nas poéticas contemporâneas, o vídeo torna-se linguagem plástica audiovisual - videocorpo - a partir da qual corpo+som+imagem compõem novas narrativas de si mesmo e do outro. No Brasil, a produção da arte do vídeo que tem a arte da performance e o corpo como mote, se apresenta cada vez mais associada a questões e proposições que envolvem trabalhos experimentais e autorais, interessados em assumir pontos de vista sobre o mundo, mas também dispostos a criar novas linguagens, hibridas e polifônicas (MACHADO, 2007). Neste sentido, o videocorpo é síntese da experiência de si mesmo e do outro e o dispositivo videográfico, a presentificação do meu corpo no corpo do outro.

\section{Referências}

AGAMBEN, G. O que é um dispositivo?. In: outratravessia. Florianópolis, n. 5, jan. 2005. p.9-16, Disponível em: <https://periodicos.ufsc.br/index.php/Outra/article/view/12576>. Acesso em: 14 jul. 2016.

BELTING, H. Imagem, Mídia e Corpo: Uma nova abordagem à Iconologia. In: Revista Ghrebh-, Imagens e Mediações, vol. 1, no. 08, 2006. p.32-60. Disponível em: <http://www.revista.cisc.org.br/ghrebh/index.php?journal=ghrebh\&page=article\&op=view\&path\%5B\%5D=178\&path\%5B\%5D=189>. Acesso em: 14 jul. 2016.

CAPRA, F. As conexões ocultas: ciência para uma vida sustentável. 7ạ. ed. São Paulo: Cultrix, 2011. 296p.

DELEUZE, G. "O que é um dispositivo". In: O mistério de Ariana. Lisboa: Vega, $1996, \mathrm{~s} / \mathrm{p}$.

ENTRE. Nina Galanternick, edt. Videoarte. 1999. Disponível em: < http://ninagalanternick.com/Entre-1> Acesso em: 21 de abr. 2018. 
FLUSSER, V. Filosofia da Caixa Preta. Ensaios para uma futura filosofia da fotografia. São Paulo: Annablume, 2011.108p.

FLUSSER, V. O Universo das Imagens Técnicas. Elogio da superficialidade. São Paulo: Annablume, 2008. 150p.

FOUCAULT, M. Microfísica do poder. São Paulo: Edições Graal, 2003. 430p.

MACHADO, A. Made in Brasil. Três décadas do vídeo brasileiro. São Paulo: Iluminuras, 2007. 443p.

SARZI-RIBEIRO, R. A. Regimes de visibilidade do corpo fragmentado e construção de sentido e interação na videoarte brasileira. São Paulo. Tese (Doutorado). Pontifícia Universidade Católica - PUC, São Paulo - SP. 2012, 384p. 